\title{
Juvenile Gaucher's disease with horizontal gaze palsy in three siblings
}

\author{
J. H. TRIPP, B. D. LAKE, E. YOUNG, J. NGU, AND E. M. BRETT \\ From The Hospital for Sick Children and the Institute of Child Health, London, and \\ Clinical Division, WSS University of Yaounde, Republic of Cameroun
}

SUMMARY Three children in a West African family had Gaucher's disease of juvenile onset (Type 3), and all showed an identical neurological disorder. The diagnosis was substantiated by histochemical demonstration of Gaucher cells in bone marrow, liver, and spleen, the finding of an excess of glucosyl ceramides in a liver extract, and a deficient activity of the enzyme $\beta$-glucosidase in cultured skin fibroblasts. The neurological picture was characterised by myoclonic epilepsy, muscle wasting, hypotonia, pyramidal signs, some intellectual deterioration, and a striking disturbance of eye movements. The latter appears to result from specific involvement of the supranuclear pathways subserving lateral gaze. The distinctive features of this clinical syndrome are emphasised.

Gaucher's disease is a recessively inherited condition characterised by a deficient activity of the lysosomal enzyme glucocerebroside $\beta$ glucosidase (Brady et al., 1965 ; Patrick, 1965) and consequent accumulation of glucocerebroside.

Two main forms of the disorder are recognised (Fredrickson and Sloan, 1972), a chronic nonneuronopathic form usually affecting adults (Type 1), and an acute neuronopathic form affecting infants (Type 2). The first type may present at any time from birth to old age, the earliest symptoms commonly being due to hypersplenism - for example, anaemia or bruising - or to bony lesions-for example, pain or spontaneous fractures. The acute neuronopathic form is usually manifest before the age of 6 months and fatal by the age of 2 years, the average survival being only 9 months. This rapidly progressive condition is associated with developmental arrest and marked involvement of the cranial nerves and brain stem.

There are a number of earlier reports in the literature of intermediate cases which have been labelled the subacute neuronopathic (Juvenile or Type 3) form, presenting in later childhood with neurological manifestations (Fredrickson and Sloan, 1972). In their critical review these authors point out that the documentation in many reports does not allow all the cases to be accepted as Gaucher's disease. Recent descriptions of two siblings (Miller et al., 1973), and of a single patient (King, 1975), report the onset of a neuronopathic form of Gaucher's disease in adult

Accepted 2 December 1976 life. From the published reports of Type 3 Gaucher's disease, a very variable clinical picture of the disease emerges.

The present report describes clinical, histochemical, and biochemical findings in three siblings with Gaucher's disease who had a distinctive clinical disorder with myoclonic epilepsy and specific involvement of the supranuclear pathways mediating horizontal gaze.

\section{Case reports}

The three children reported here were members of an African family of nine children from the Besongabong tribe in West Cameroon, both parents being members of the tribe and distantly related (Fig. 1). The father (Jo), aged 45 years, is well and working as an executive civil servant; he had been married previously to Ag who died of an unrelated infectious disease, and by this marriage had a son (Em) who is well at the age of 23 years, and is in the police force.

The mother (He), aged 40 years, is partially sighted as a result of variola infection of the cornea but is otherwise well. Es, the eldest child, a girl aged 22 years who graduated from secondary school and now helps at home, is physically and mentally well.

$\mathrm{Ri}$, a boy aged 20 years, is well and takes school leaving certificate this year. Ja, Go, and Tab all had Gaucher's disease and are discussed in detail below. $\mathrm{Br}$, a girl aged 12 years, is doing well at primary school, as are the younger brothers, Eb aged 8, and Tak aged 6 years. 


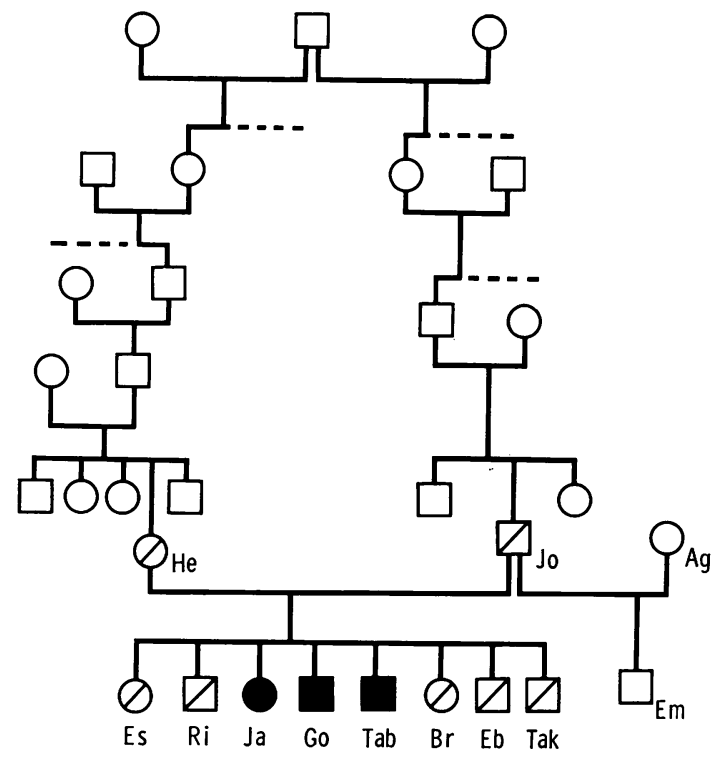

$\square \square \square$ MALE NOT SEEN / SEEN / AFFECTED

$\bigcirc \oslash$ FEMALE NOT SEEN / SEEN / AFFECTED

Fig. 1 Simplified family tree of index patients showing relationship of their parents.

\section{CASE 1}

$\mathrm{Ja}$, the eldest affected child, was normal and healthy until the age of 9 years, having been above average in school performance. During her tenth year she began to sleepwalk, and shaking of her hands was noticed while feeding or writing. Later that year she had a major convulsion, and over the following three years she became increasingly physically incapacitated and had frequent fits. She became progressively clumsy, and her speech was affected, being very quiet but clear. No other abnormalities were noted by the family. Investigations were undertaken elsewhere including a bone marrow examination, and a diagnosis of Niemann-Pick disease was suggested. She died at the age of 14 years.

CASE 2

Her younger brother Go had been previously well apart from episodes of fever presumed to be due to malaria, and had learnt to read and write by the age of 7 years. Two years after the onset of Ja's illness, during his ninth year, Go began to have screaming attacks and episodes of inexplicable aggressive behaviour later developing into major convulsions. During his tenth year he had further fits but continued at school complaining only of stiffness in his limbs.
His fits became more frequent and assumed a characteristic pattern beginning with jerking and progressing to gross movements of his arms which gradually became more violent, and then involved the whole body in a major convulsion with unconsciousness and often double incontinence. By the age of 11 years all voluntary movements were difficult, and he could no longer dress or feed himself. Anticonvulsants were unhelpful and were discontinued after a short time. At 13 years of age he was transferred to the United Kingdom for further investigations, and was initially under the care of Dr R. Kelly who referred him to one of us (EMB).

On examination, Go was of normal height and was pubertally mature but had recently lost weight with generalised muscle wasting. He was alert and cooperative, and his remote and recent memory were good. Psychometric assessment (Wechsler Intelligence Scale for Children) showed him to have a full scale IQ of 76. The spleen was palpable below the level of the umbilicus and was firm, but the liver was not enlarged, and there was no lymphadenopathy, anaemia, or jaundice. Almost continuous myoclonic jerks affected his limbs, face, and tongue, and similar movements involved his eyes; in addition he had a tremor of his outstretched hands, resembling the flapping tremor of hepatic precoma (asterixis) which later disappeared. He had frequent major convulsions which began in the arms and became generalised. These could sometimes be aborted by reassurance at the stage when only his arms were involved. His speech was dysarthric, being slow, indistinct, and very quiet.

The visual fields, acuity, and fundoscopic appearances were normal. There was no ptosis, and the pupils were equal and had normal responses bilaterally. Visual axes were parallel, and there was no abnormality of vertical gaze. In contrast, he had a striking abnormality of horizontal gaze. During the earlier part of his admission he was able to deviate his eyes to about $10-15^{\circ}$ to either side while following a slow-moving object but not to command. Later this ability disappeared. Optokinetic nystagmus and the doll's eye phenomenon (the oculocephalic reflex) were normal. There was no nystagmus, and the only other cranial nerve abnormality was a brisk jaw jerk. Tone in his limbs and trunk was grossly reduced. Power of voluntary movements was uniformly grade 4 (MRC scale). He could walk if supported, and could sit in a chair supported behind and at each side. During convulsions, the power of his muscles was that of a full-grown man, and three or four adults were required for restraint. Deep tendon reflexes in upper and lower limbs were pathologically brisk with ankle clonus but plantar responses were flexor. Because of his weakness and myoclonus no con- 
clusions as to the presence or absence of true cerebellar ataxia were possible. Sensation was normal. His fits were difficult to control even with adequate doses of phenobarbitone and phenytoin, and an episode of status epilepticus lasting 24 hours was terminated only by diazepam infusion. Go has since died. No necropsy was performed.

\section{Investigations}

The blood contained haemoglobin $13.1 \mathrm{~g} / \mathrm{dl}$, white blood cells $4.1 \times 10^{9} / 1$, reticulocytes $5-6 \%$ of RBCs, platelets $60-90 \times 10^{9} / 1$, ESR $55-120 \mathrm{~mm}$ in first hour. Serum proteins $(\mathrm{g} / \mathrm{dl})$ total 8.8 , albumin 3.8 , globulin 5.0, immunoglobulins (IU), IgA 105, IgG 370, IgM 1128. Thick films and cultures of peripheral blood, bone marrow, splenic smears, and a liver biopsy specimen were all negative for malaria, trypanosomiasis, leishmaniasis, and schistosomiasis. High titres of complement-fixing antibodies to embryonic Onchocerca volvulus (Ngu and Blackett, 1976) were found. Plasma bilirubin, alkaline phosphatase, and transaminases were all normal. Plasma acid phosphatase $12.9 \mathrm{IU} / \mathrm{l}$ (raised) had a normal prostatic component. Prothrombin and partial thromboplastin times were prolonged by $50 \%$ compared with control, with no improvement after intramuscular vitamin K. A bromosulphthalein excretion test showed increased retention with $13 \%$ of administered dye remaining at $\mathbf{4 5}$ minutes. Barium swallow was normal, and stool examinations for occult blood were negative. Skull radiographs showed thickening of the vault consistent with cerebral atrophy. Radiographs of the long bones showed areas of cystic rarefaction in the ulnae, radii, femora, and tibiae (Fig. 2). No Erlenmeyer flask deformity was apparent.

Electroencephalography (Dr G. Pampiglione) showed a grossly disorganised record with extremely frequent multifocal discharges which often coincided with clinical myoclonus, and bursts of muscle action potentials recorded in the polyelectromyograph (Fig. 3).

\section{Histological, histochemical, electronmicroscopic and biochemical studies}

Snap-frozen, formalin fixed frozen, and formalin fixed, paraffin wax embedded liver was examined by histochemical, histological, ultrastructural, and thinlayer chromatographic methods described by Neville et al., (1973). Bone marrow films were stained with the May-Grunwald-Giemsa sequence, with the periodic acid Schiff reaction (PAS), with Sudan black, and to demonstrate the activity of acid phosphatase. A rectal biopsy sample was taken under general anaesthetic (Smith et al., 1976), and cryostat sections were prepared and stained as described by Bodian and Lake (1963) and Brett and Lake (1975).
A small biopsy specimen of spleen was processed for routine histology only.

Bone marrow films contained comparatively few storage cells identified on the basis of their staining reactions with PAS, Sudan black, for acid phosphatase activity, and their appearance in MayGrunwald-Giemsa preparations. The cytoplasm of the storage cells resembled crumpled tissue paper, stained with PAS, and showed strong acid phosphatase activity, appearances identical with those found in Gaucher's disease. The rectal biopsy specimen was normal and showed no changes in the mucosa, neurones, or muscle. The biopsy specimen of liver showed a normal architecture with scanty storage cells characteristic of Gaucher cells. The hepatic parenchymal cells were not involved. The spleen and lymph node contained numerous cells of the Gaucher type. Electron microscopy (Fig. 4) showed the characteristic inclusions of Gaucher's disease (Brady and King, 1973).

Fibroblasts cultured from a skin biopsy showed low activity of $\beta$-glucosidase and a low ratio of $\beta$-glucosidase to $\beta$-galactosidase activities (Table 1) consistent with Type 1 Gaucher's disease (see Discussion).

Thin-layer chromatography of a lipid extract of the liver showed an excess of a substance with the mobility and characteristics of cerebroside (Fig. 5). No other abnormalities were found.

CASE 3

When the diagnosis had been established in Go, one of us (JHT) was fortunate in being able to accompany him back to the Cameroon and there to see the rest of the family and, in particular, his younger affected brother Tab, aged 11 years.

Tab became ill when he was 10 years old, the disease progressing in an identical fashion to that of Go, though rather more rapidly. When seen at age 12 years he had already reached the stage of Go, though a year younger, and was totally incapacitated. On examination he had severe difficulties with voluntary movements, very slow and quiet speech, but good understanding and no obvious dementia. He had continuous myoclonic jerks and frequent major convulsions, also starting in the arms. He had a disorder of eye movement identical to his brother, with loss of horizontal but preservation of vertical gaze, parallelism of his visual axes, normal pupillary reflexes, and normal retinae. He had gross hypotonia of trunk and limbs with muscle wasting but pathologically brisk deep tendon reflexes, ankle clonus, and flexor plantar responses. He also had a grossly enlarged spleen, but no hepatomegaly. He has since died. Limited investigations showed: $\mathrm{Hb} 9.9 \mathrm{~g} / \mathrm{dl}$, platelets $95 \times 10^{9} / 1$, plasma acid phosphatase 17.6 IU/1 with a normal 

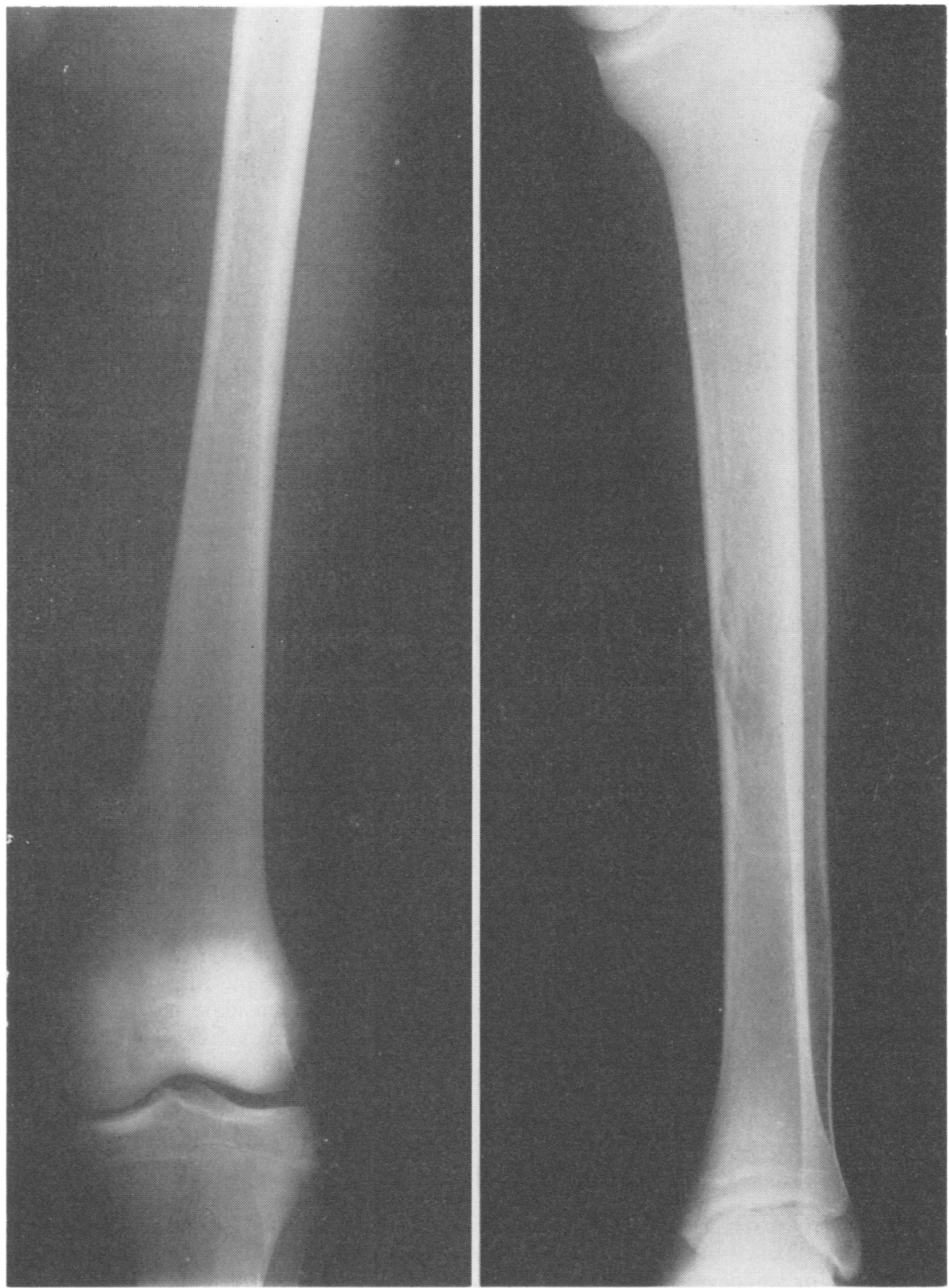

Fig. 2 Radiographs of left leg of patient Go show areas of cystic rarefaction in the tibia but no Erlenmeyer flask deformity of the femur.

prostatic fraction and a grossly raised immunoglobulin (IgM) of $628 \mathrm{IU} / 1$ with normal IgA and IgG. Bone marrow and needle liver biopsy specimens showed similar cells to those found in his brother, with identical histochemical staining reactions. Skin fibroblast cultures showed similar enzyme activities of $\beta$-glucosidase and $\beta$-galactosidase to his brother Go (Table 1).

FAMILY

Clinical examination of both parents and all the other children were normal apart from mild hepatomegaly 


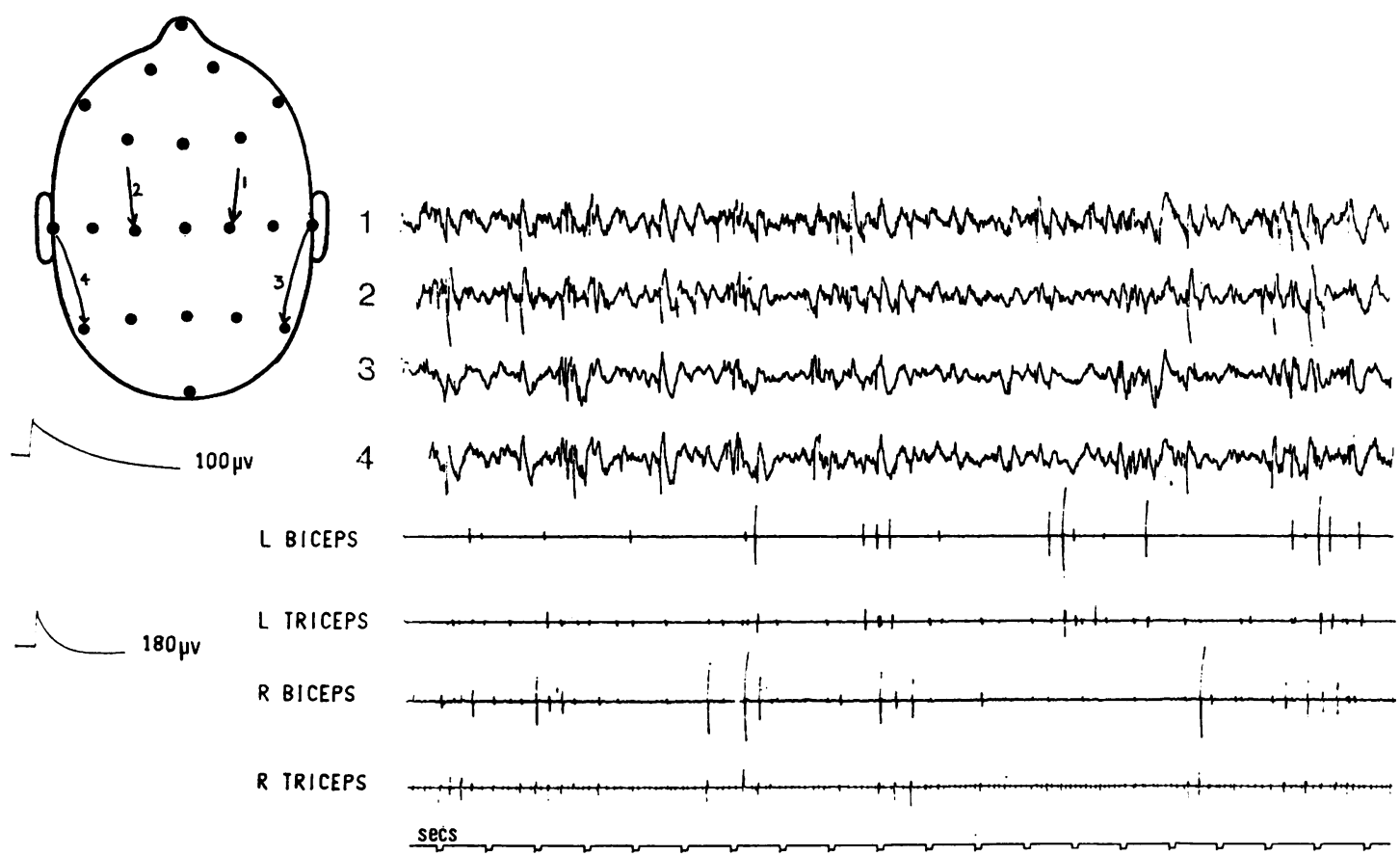

Fig. 3 Simultaneous EEG and polyEMG record of patient Go.

detected in Eb. Enzyme assays were performed in skin fibroblast cultures in all members of the family (except $\mathrm{Eb}$ whose culture failed to grow), and the results (Table 1 ) show normal ratios of $\beta$-glucosidase to $\beta$-galactosidase activity in all except the two index cases tested. Plasma acid phosphatase was normal in all except the two index cases.

\section{Discussion}

In the past the diagnosis of Gaucher's disease depended on the clinical features and the pathological finding of characteristic storage cells in the spleen or bone marrow. The staining properties of these cells enable a pathological distinction to be made from other somewhat similar disorders such as NiemannPick disease. The demonstration of a deficient activity of glucocerebrosidase in spleen, liver, brain, or cultured fibroblasts or leucocytes is now accepted as the definitive investigation, and has recently been demonstrated in Type 3 (Murphy et al., 1976), and in the patients of Miller et al (1973), and King (1975).

Skin biopsy samples were obtained from all the present family except $\mathrm{Ja}$ but the subsequent cultures all developed intracellular infections, the severity of which varied between cultures and were thought to be inherent in the biopsy specimens. Attempts to culture fibroblasts from Eb's biopsy were unsuccessful.
In view of the difficulties encountered in the culture of cells from this family, use was made of the fact, shown by Young et al. (1975), that a clearer differentiation of a relative deficiency of a given enzyme may be obtained by expressing its activity as a ratio to that of another enzyme. In this family, the $\beta$-glucosidase activity in the two affected children Go and Tab was within the range found in cases of Type 1 Gaucher's disease. The $\beta$-glucosidase activity was also low in two apparently healthy members of the family, Es and $\mathrm{Br}$; however, the ratio $\beta$-glucosidase: $\beta$-galactosidase in the latter two was double that found in Go and Tab, and within the range of control subjects (Table 1). In this family, the diagnosis is firmly established clinically, histochemically, and biochemically in the two boys seen and tested (Go and Tab), and it is almost certain that their sister $\mathrm{Ja}$ had the same condition.

The similarity of the clinical features in these three children is evidence of a neurological syndrome with specific pathophysiology in this family, and in this resembles certain other recessively-inherited metabolic disorders (for example, Tay-Sachs disease and metachromatic leucodystrophy) which commonly result in identical symptoms and signs in siblings. We were struck by this uniformity of symptoms and signs in our patients especially when compared to the wide variation of symptoms and signs in previous reports. 


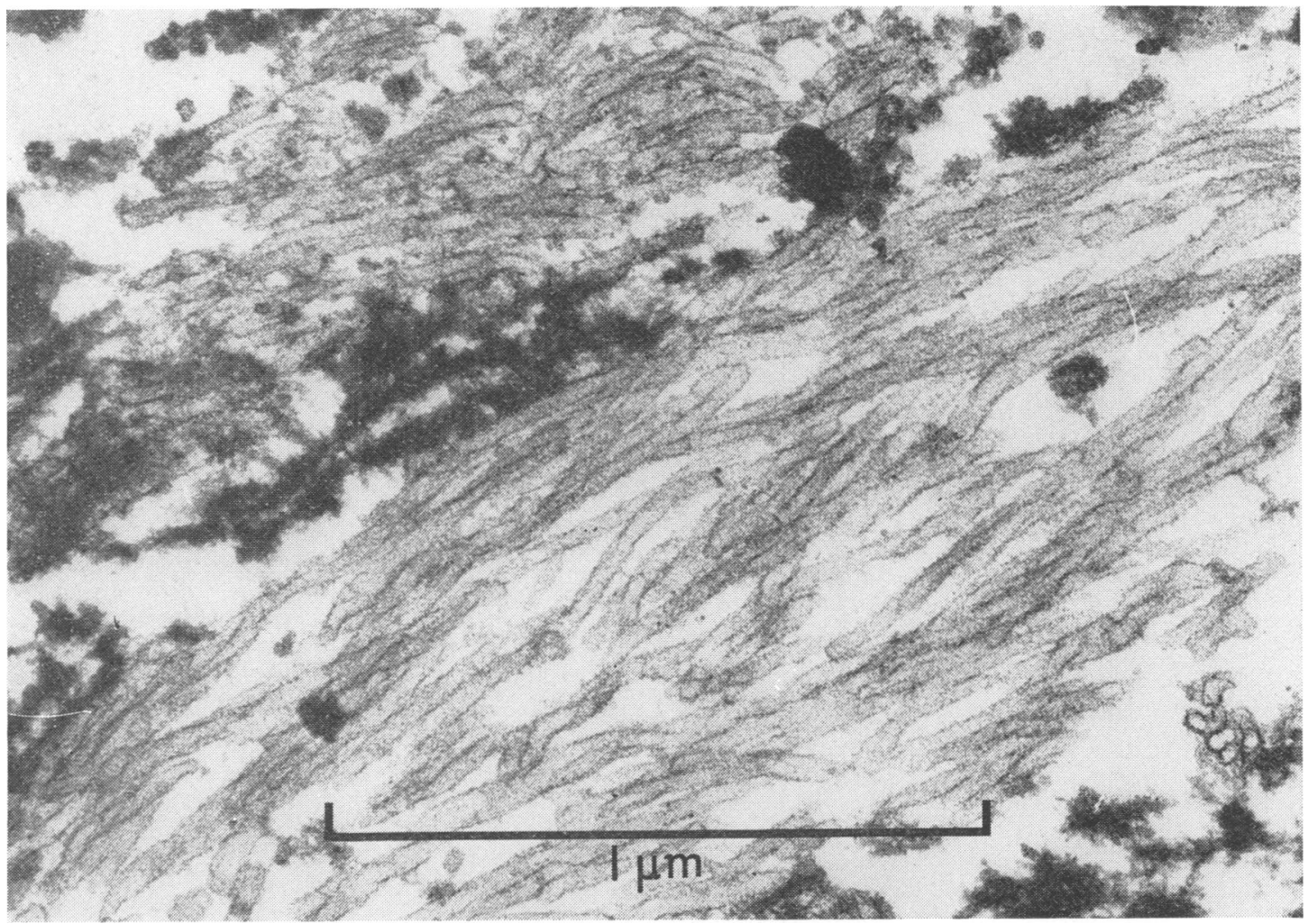

Fig. 4 Electronmicrograph of a portion of a Gaucher cell from the liver of patient Tab showing characteristic tubular inclusions of cerebroside.

Table $1 \quad \beta$-glucosidase and $\beta$-galactosidase activities in cultured skin fibroblasts

\begin{tabular}{lccl}
\hline Subject & $\begin{array}{l}\beta \text {-glucosidase } \\
\text { (nmol/mg soluble }\end{array}$ & $\begin{array}{c}\beta \text {-galactosidase } \\
\text { protein/hr) }\end{array}$ & $\begin{array}{l}\beta-g ! u \\
\beta-g a l\end{array}$ \\
\hline Go (case 2) & 42 & 898 & 0.05 \\
Tab (case 3) & 44 & 1401 & 0.03 \\
Jo (father) & 149 & 942 & 0.16 \\
He (mother) & 121 & 702 & 0.17 \\
Em & 120 & 569 & 0.21 \\
Es & 72 & 960 & 0.08 \\
Ri & 276 & 1309 & 0.21 \\
Br & 95 & 1111 & 0.09 \\
Tak & 176 & 1354 & 0.13 \\
Controls \pm SD & $239 \pm 109$ & $1671 \pm 607$ & $0.16 \pm 0.08$ \\
$\quad$ (45) & & & \\
Gaucher disease \pm SD & $47 \pm 21$ & $1387 \pm 364$ & $0.04 \pm 0.02$ \\
$\quad$ Type 1 & & & \\
(8) & & & \\
\hline
\end{tabular}

* $\beta$-glucosidase assay mixture contained $0.4 \%$ human albumin $(20 \mu \mathrm{l})$ $6 \mathrm{mmol} / 1$ 4-methylumbelliferyl- $\beta$-D-glucopyranoside in McIlvaine's citrate-phosphate buffer pH $4.5(50 \mu \mathrm{l})$, and cell homogenate $(30 \mu \mathrm{l}$ containing 15-25 $\mu \mathrm{g}$ soluble protein). After incubation at $37^{\circ} \mathrm{C}$ for $30 \mathrm{~min}, 0.25 \mathrm{~mol} / 1$ glycine- $\mathrm{NaOH}$ buffer $\mathrm{pH} 10.4(2.4 \mathrm{ml})$ was added, and the liberated 4-methylumbelliferone measured fluorimetrically.

$+\beta$-galactosidase assay mixture contained $1 \mathrm{mmol} / \mathrm{l}$ 4-methylumbelliferyl- $\beta$-D-galactopyranoside in McIlvaine's citrate-phosphate buffer pH $4.1(150 \mu \mathrm{l})$, and $0.4 \%$ human albumin in $0.4 \mathrm{~mol} / 1 \mathrm{NaCl}(50 \mu \mathrm{l})$ containing cell homogenate equivalent to 2-4 $\mu \mathrm{g}$ soluble protein. After incubation for $15 \mathrm{~min}$ at $37^{\circ} \mathrm{C}, 0.25 \mathrm{~mol} / 1$ glycine-NaOH $\mathrm{pH} 10.4$ (2-3 $\mathrm{ml})$ was added, and the fluorescence measured.

Protein was determined by the method of Lowry et al. (1951).
We have reviewed reports concerning patients who fulfilled clinical and biochemical diagnostic criteria (Fredrickson and Sloan, 1972), and have included the patients of Reiss and Kato (1932), Maloney and Cumings (1960), Herrlin and Hillborg (1962), together with the reports of neurological disease in adults with Gaucher's disease (Miller et al., 1973; King, 1975).

All the patients in this family presented with convulsions which were also a feature of all the previously described cases (Table 2). Psychomotor fits, described in the patients of Herrlin and Hillborg at the time of diagnosis, also probably occurred in Go. The onset of the fits in the first patient of Miller et al. (1973), each being preceded by random gross movements of the upper limbs, was similar to the picture seen in both Go and Tab. The patient reported by King was diagnosed as having 'progressive myoclonic epilepsy', and four others of the previously described patients probably also had myoclonus (Table 2). The flapping tremor seen in Go during the early part of his admission may have been ictal in origin although this could not be proved as it did not persist during any electroencephalographs. The asterixis described 
Fig. 5 Thin-layer chromatography of lipid extracts. Tracks: $1=$ Gaucher liver; $2=$ normal liver; $3=$ Patient Go liver. Extract from $10 \mathrm{mg}$ tissue applied. Solvent system: Chloroform, methanol, water $(70: 30: 5 v / v)$. Silica gel plate sprayed with diphenylamine. by Miller et al. in both their patients was apparently similar to that of Go, and they also excluded hepatic failure as a cause. Non-specific abnormalities of the electroencephalographs with diffuse slow waves and paroxysmal activity were seen in Go, and are described in previous reports (Table 2).

Difficulties with voluntary movements appear to be frequent in this condition, occurring in all but three of the patients described in the reports under review. In our patients, and in one of those described by Miller et al., speech was slow and slightly indistinct, and we attribute the dysarthria of Go and Tab to their difficulties with voluntary movements and underlying pyramidal disorder.
The most striking abnormality in our patients was the disorder of eye movement which was a defect of voluntary lateral gaze with normal doll's eye phenomenon, vertical gaze, and parallelism. Go, when seen early during his admission, was able to deviate his eyes laterally further when following a slow-moving object than a fast-moving object or to command, suggesting a primary defect involving the saccadic system controlling lateral gaze-that is, the frontopontine pathway-and later the pursuit systemthat is, the occipito-pontine pathway-but sparing the vestibular-pontine pathway, and also sparing all three systems acting on the pretectal gaze centre to control conjugate vertical gaze. Similar eye signs were 
Table 2 Neurological symptoms and signs in reported cases of juvenile Gaucher's disease

\begin{tabular}{|c|c|c|c|c|c|c|}
\hline Symptom/sign & $\begin{array}{l}\text { Reiss and Kato } \\
\text { (1932) }\end{array}$ & $\begin{array}{l}\text { Maloney and } \\
\text { Cumings }(1960)\end{array}$ & $\begin{array}{l}\text { Herrlin and } \\
\text { Hillborg (1962) }\end{array}$ & $\begin{array}{l}\text { Miller et al. } \\
\text { (1973) }\end{array}$ & King (1975) & This report \\
\hline Number of patients & $3 *$ & 1 & 6 & 2 & 1 & $3 *$ \\
\hline \multicolumn{7}{|l|}{ Epilepsy: } \\
\hline Grand mal & 2 & 1 & 3 & 2 & 1 & 2 \\
\hline Psychomotor & 0 & 0 & 3 & 0 & 0 & 1 \\
\hline Myoclonic & $2 \dagger$ & 0 & $2 \dagger$ & 0 & 1 & 2 \\
\hline (Asterixis) $\ddagger$ & NR & NR & NR & 2 & NR & 1 \\
\hline Epilepsy as presenting feature & 0 & 1 & 0 & 1 & 1 & 2 \\
\hline EEG abnormality & NR & 1 & 6 & 2 & 1 & $1 \S$ \\
\hline Gaze disorder & $2 \|$ & 0 & $3 \|$ & 2 & 1 & 2 \\
\hline Speech disorder & NR & NR & NR & NR & 1 & 2 \\
\hline Movement disorder & 2 & NR & 5 & 2 & 1 & 2 \\
\hline Weakness/muscle wasting & NR & NR & 1 & 2 & NR & 2 \\
\hline Hyperreflexia & 2 & 1 & 0 & 0 & 0 & 2 \\
\hline Plantar responses & $\downarrow$ & $\uparrow$ & $\downarrow$ & $\downarrow$ & $\downarrow$ & $\downarrow$ \\
\hline Ataxia & $\mathbf{R}$ & 1 & 1 & 2 & 1 & 2 \\
\hline Retardation & 2 & 1 & 6 & 2 & 1 & 2 \\
\hline
\end{tabular}

NR $=$ not recorded.

* Only two patients examined and investigated fully.

$\dagger$ 'Twitching movements' reported.

$\ddagger$ Movements resembling flapping tremor of hepatic failure which are presumed to be ictal (see Discussion).

Only one patient tested.

II Abduction defect or VI nerve palsy reported.

seen in the patients reported by Miller et al. (1973); vertical gaze was also involved, but to a lesser extent, and in their second patient, horizontal gaze only was affected as in our patients. In the patient reported by King (1975), saccadic eye movements were 'slow' in all directions. Other disturbances of extraocular movements, especially abduction (apparently a cranial nerve palsy), are described in other reports (Table 2). We suggest that Gaucher's disease with neurological involvement in the juvenile or adult group may result in this very specific clinical sign (suggesting localised pathological changes) in a similar way to the vertical gaze palsy seen in the ophthalmoplegic lipidosis syndrome (Neville et al., 1973). There are thus two lipid storage disorders in which careful examination of the supranuclear control of eye movements may be helpful diagnostically, and furthermore, in gaze palsies, inherited metabolic disease must be considered.

Both patients had generalised hypotonia and muscle wasting in the presence of pyramidal signs. Tendon reflexes are recorded as brisk in previous reports though not in those with muscle wasting (Table 2). In no case was extensor plantar responses found, except possibly that of Maloney and Cumings (1960) whose patient is recorded as having brisk reflexes and a 'primitive' Babinski sign.

In contrast with the infantile form of the disease in which gross developmental delay and/or regression may occur as an early feature, the intellect in our patients was relatively well-preserved. Thus, all three patients in this family were of at least normal intelligence until the age of 7 years or later, and, even when totally physically incapacitated, Go was able to score
76 on formal intelligence testing. Moderate retardation or low IQ is recorded in most of the patients reviewed but in no case was an IQ of less than 70-80 obtained.

Both the children we were able to investigate had skeletal abnormalities which are commonly associated with the adult non-neuronopathic disease. Herrlin and Hillborg (1962) also reported the development of bony changes which they suggested were related to previous splenectomy. Our patients, however, have not had splenectomies. A further abnormality in our patients is the presence of gammaglobulin in excess, both Go and Tab having grossly raised serum IgM levels. We did not think that these high levels were due to tropical disease. The fact that this increase was restricted to $\operatorname{IgM}$ while the complement fixing (CF) antibodies were both $\mathrm{IgM}$ and $\mathrm{IgG}$, together with the extremely high IgM levels in the patients but not in the other members of the family suggests that this was a primary defect and not solely antibody to Onchocerca volvulus. Abnormally raised gammaglobulins, which are usually monoclonal in type, have been reported previously in adults with Type 1 Gaucher's disease (Pratt et al., 1968) but not in Type 3.

As mentioned above, there was a striking concordance of the presenting symptoms, signs, and outcome of the illness in these three siblings. In the literature we have found that the opposite conclusion has been reached in the past; for example, exactly half of the extended family affected with Gaucher's disease described by Herrlin and Hillborg (1962) had the acute infantile form and half had a subacute juvenile form, while only two of at least three affected adults reported by Miller et al. (1973) had neurologi- 
cal complications. These apparent anomalies with the existence of families such as ours in which a typical recessive pattern of inheritance appears to be present, and others in which the disease seems to vary between siblings may be explained by the presence of some other modifying factor or gene.

JHT would like to thank Mr Hugh Greenwood and the Children's Research Fund who made the visit to the Cameroon Republic possible. The authors would like to thank Dr P. Kennedy for helpful criticism, and Miss Elisabeth Moore for patience and secretarial assistance.

\section{References}

Bodian, M. and Lake, B. D. (1963). The rectal approach to neuropathology. British Journal of Surgery, 50, 702714.

Brady, R. O., Kanfer, J. N., and Shapiro, D. (1965). Metabolism of glucocerebrosides. II Evidence of enzymatic deficiency in Gaucher disease. Biochemical and Biophysical Research Communications, 18, 221-5.

Brady, R. O., and King, F. M. (1973). Gaucher's Disease. In Lysosomal and Storage Diseases. Edited by H. G. Hers, and F. Van Hoof. Academic Press: London.

Brett, E. M., and Lake, B. D. (1975). Reassessment of rectal approach to neuropathology in childhood. Review of 307 biopsies over 11 years. Archives of Disease in Childhood, 50, 753-762.

Fredrickson, D. S., and Sloan, H. R. (1972). Glucosyl ceramide lipidoses. In The Metabolic Basis of Inherited Disease. pp. 730-759. Edited by J. B. Stanbury, J. B. Wyngaarden, and D. S. Fredrickson. McGraw Hill: New York.

Herrlin, K. M., and Hillborg, P. D. (1962). Neurological signs in the juvenile form of Gaucher's disease. Acta Paediatrica (Uppsala), 51, 137-154.
King, J. O. (1975). Progressive myoclonic epilepsy due to Gaucher's disease in an adult. Journal of Neurology, Neurosurgery, and Psychiatry, 38, 849-854.

Lowry, O. H., Rosenbrough, N. J., Farr, A. L., and Randall, R. J. (1951). Protein measurement with the folin phenol reagent. Journal of Biological Chemistry, 193, 265-275.

Maloney, A. F. J., and Cumings, J. N. (1960). A case of juvenile Gaucher's disease with intraneuronal lipid storage. Journal of Neurology, Neurosurgery, and Psychiatry, 23, 207-213.

Miller, J. D., McCluer, R., and Kanfer, J. N. (1973). Gaucher's disease: neurologic disorder in adult siblings. Annals of Internal Medicine, 78, 883-887.

Murphy, J. V., Glew, R. F., and Peters, S. P. (1976). Deficient glucocerebrosidase activity in Gaucher's disease, type III. Pediatric Research, 10, 368 (Abstract).

Neville, B. G., Lake, B., Stephens, R., and Sanders, M. D. (1973). A neurovisceral storage disease with vertical supranuclear ophthalmoplegia. Brain, 96, 97-120.

Ngu, J. L. and Blackett, K, (1976). Immunological Studies in Onchocerciasis in Cameroon. Tropical and Geographical Medicine, 28, 111-120.

Patrick, A. D. (1965). A deficiency of glucocerebrosidase in Gaucher's disease. Biochemical Journal, 97, 170.

Pratt, P. W., Estren, S., and Kochwa, S. (1968). Immunoglobulin abnormalities in Gaucher's disease: report of 16 cases. Blood, 31, 633-640.

Reiss, O., and Kato, K. (1932). Gaucher's disease: a clinical study with special reference to the roentgenology of bones. American Journal of Diseases of Children, 43, 365-386.

Smith, P., Dickson, J. A. S., and Lake, B. D. (1976). Rectal biopsy in the diagnosis of neurological disease in childhood. British Journal of Surgery, 63, 313-316.

Young, E., Wilcox, P., Whitfield, A. E., and Patrick, A. D.尹 (1975). Variability of acid hydrolase activities in cultured skin fibroblasts and amniotic fluid cells. Journal of Medical Genetics, 12, 224-229. 